\title{
VISUALISING GLOBAL PANDEMIC: A CONTENT ANALYSIS OF INFOGRAPHICS ON COVID - 19
}

\author{
Rachel Jacob \\ Assistant Professor and Head, Department of Journalism \\ Madras Christian College Chennai \\ Tamil Nadu, India
}

\begin{abstract}
Visuals and words always create a narrative impact on the minds of the readers. Visual data or infographics enable readers to understand and comprehend complex information effortlessly. In an era of technological development, consumption of information is faster and quicker, and so the storytelling potential of data visualisation narratives is productive. During a global endemic like coronavirus, the mounting fear motivates people to seek accurate and credible information swifter and also change health behaviour accordingly. This paper tries to explore the representation of visualisation of data during the outbreak of global pandemic - COVID-19 for three months - from 1 January to 21 March 2020 in two leading national newspapers - The Hindu and The Times of India. The study identified the percentage of coverage, different levels and types of infographics and message characteristics of infographics. The study found that response and self-efficacy related infographics were primarily less in number compared to severity and vulnerability. Media needs to adorn a robe of 'social responsibility' especially during a global pandemic like coronavirus, which is sweeping across the globe - as visual message tend to have more impact than the text.
\end{abstract}

Keywords: Content Analysis, Coronavirus, COVID-19, EPPM, Infographic

\section{INTRODUCTION}

Infographics - Readers' delight! Skimming through daily newspapers and magazines, or scrolling social networking sites, we come across 'pictorials filled with information' - the new age transmission of information Infographics, which tries to inform, simplify, delight and motivate a reader. Today, individuals live in a faster and complex world, and they prefer to see and receive information in a more précis and intelligent manner. Data visualisation attempt to communicate multipart information in a manner that can be consumed and understood easily. (Smiciklas, 2012).

Infographics are widely used because "they can rapidly grab attention, simplify complex concepts and connect components of complex concepts". (Damman, Vonk, van den Haak, van Hooijdonk, \& Timmermans, 2018) They obtain the power because they tap into the very powerful (but at times eccentric) human visual information-processing system. (Kosslyn, 1985) As cited in (Otten, Cheng, \& Drewnowski, 2015), a human brain process visuals faster than text, i.e. nearly $50 \%$ of the brain is into processing visuals - human brain can sense visually in less than one-tenth of a second.

Infographics bring out the hidden stories in numbers and figures, and also a broadspectrum of information is communicated efficiently and effectively. Further, it processes multiple and enormous information through variations, thus delivering risk-bound information quicker in a limited space. (Dur, et al., 2014); (Dur, 2012)

Today, an infographic is an additional tool to elaborate on the information present in the news story (Salas, 2018) and provide a pictorial representation of 'big' events (Castaneda, 2018). The study found that there is a steady rise in the use of infographics in newspapers or interactive infographics by using set templates (Gazizov \& Fatykhova, 2019). Infographics coupled with healthrelated information can bring in a change in behaviour. Health communication aims to bring positive behaviour in an individual for combating health concerns. (Bhattacharyya \& Roy, 2016)

This paper explored the storytelling potential of an infographic from health concern (a risk communication perspective) - levels, types 
and the proportion of infographic coverage given, and understanding the message characteristics of infographics.

\section{REVIEW OF LITERATURE}

\section{A Panorama of Infographics}

Infographic's chronological viewpoint provides a peek into infographic as an effective tool in various sectors. As early as the 1600s, infographics began with the use of maps. Christopher Scheiner, in 1626, using his pantograph published sunspots, is considered as the first infographics. In the later years, in 1789, William Playfair published "Commercial and Political Atlas", which contained bar and pie charts. By 1800s, visualisation was widely used in government offices for statistical information representations, which included bubbles and 3D charts, and contour plots. In 1858, Florence Nightingale's infographic on causes of mortality in the British army facilitated in convincing the Queen to provide better health care facilities.

Similarly, in 1859, John Snow published an infographic, which portrayed the outbreak of cholera and convinced many on the spread of cholera. In 1869, Charles Minard's cartographical representation of Napolean's Russian campaign in 1812 paved the way for the extensive usage of infographics. Furthermore, by the beginning of the 19th century, we have seen a rapid growth of infographics. By 1900s, infographics were widely used in scientific and niche groups and later, by 1930s, media outlets slowly and gradually adopted it.

\section{Infographics and Journalism}

Since the 1980s, graphics were used to support the works of journalism. Usage of graphics crept into the newsroom during the 1970s and 1990s, when Peter Sullivan used graphics or visual reporting in the Sunday Times and subsequently, the USA Today newspaper, in 1982 launched - 'SnapShots', a column specifically for graphical representation of statistics. Edward Tufte often referred to as Leonard DaVinci of infographics, raced the newsrooms with infographics. By 2000s, infographic witnessed a boom in the newsrooms. Since 2009, there has been a rise in the use of the term 'infographic' to describe visualisations that use various graphics to display data and other ideas. (Ferreira, 2014)
The newspaper provides an avenue for enhancing the coverage by adding graphic along with the text, which brings in perspectives and depth to the news story. Further, graphics have become part of the news package, wherein statistics coupled with artistic design provide a story to its readers. (Giardina \& Medina, 2013)It was found that $42.4 \%$ of the newspapers run more than six infographics on an average weekday, while $43.7 \%$ of the newspapers publish more than six infographics on an average Sunday. (Utt \& Pasternak, 2000).

Infographic is found to satisfy both the needs of the editorial department of the organisation and also aids in a better understanding of the content for the readers. In today's newspaper, infographics rule the rooster - in terms of design and content. Infographics are often seen as a replacement of photographs, thus adding colour and attraction to the page. Studies suggest that infographics attract the readers to the particular article while in the case of a dominant infographic; a little more than half of the readers used it to springboard into the article (Pasternak \& Utt, 1990)

Readers tend to read and examine graphics before reading the text, and bigger graphic draw the readers to the story and also enables to highlight fewer important details. (Pasternak \& Utt, 1990); (Hollander, 1994); (Dur, et al., 2014); (Siricharoen, 2013)

Some research suggests that graphic devices allow readers to easily grasp a description of an event by making some details more prominent. (Miller \& Barnett, 2010) found that graphics with text enhance the attention as well as be beneficial to the readers.

The role of a newspaper graphic designer is known to create a graphic based on what is known and how to communicate it. (Cairo, 2006) Most graphic designs pertain to using bars and lines, initially. However, in the recent times, illustrations, iconic representations and drawings have taken precedence. (Meyer, 2009); (Cairo, 2006) Information related to sales growth and fall, the incidence of illness, do's, and don'ts, travel itinerary, medal tally are represented visually for easy understandability. (Few, 2017) 
In the field of medicine, data visualisations were being used as early as the 1850 s to create visual arguments based on data. In 1858, Florence Nightingale used medical data to create a coxcomb chart, which revealed the significant difference between the numbers of soldiers dying due to sanitary conditions versus battlefield wounds during the Crimean War (Brigham, 2016);(McCrorie, Donnelly, \& McGlade, 2016). These infographics are intended to translate complex health-care information into simplified graphical snapshots that will leave the readers with a better understanding of how a disease can occur, be treated, and possibly even be prevented. (Balkac \& Ergun, 2018)

For risk communication in a crisis like coronavirus pandemic, it is essential to communicate clearly, precisely as well as accurately to the target audience. Visual designers place the risk in 'context and perspective' to provide an understanding of the risks involved. In times of crisis, people hover with many questions - What, Who, Why, How? It is during this time, data coupled with the right tool will enable readers to see patterns and trends, which is sometimes invisible. During health outbreaks, it is crucial to disseminate the credible and reliable message, as false information creates an environment of 'infodemic'.

\section{Types of infographics}

Infographics may take various shapes and contours, but the three main categories are: data graphics, maps, and diagrams whichcan be either static (for print or screen use), animated or interactive (for screen use) (Otten, Cheng, \& Drewnowski, 2015), while some studies categorise infographics as data visualisation or statistical (tables, lists, lines and bar charts), informational design or timeline or chronology (timelines, chronology, flowcharts, comparisons, hierarchical and anatomical illustrations), process infographics (a linear process of a topic) and editorial (icons and symbols) (Siricharoen, 2013). Albers (2015) in his study highlights four-types of infographics: simple information graphic bullet list, and snapshot with graphic needs, and complex information graphic- flat information with graphic needs, and information flow/process.
In the field of healthcare, according to (McCrorie, Donnelly, \& McGlade, 2016) there are four infographics: isotype array which uses similar icons or symbols; polar area diagram or coxcomb graph, a representation of pie and bar charts; word cloud, (hub and spokes) a cluster of words (spokes) arranged hierarchically according to prominence, size, colour around a hub (a central word); and charticle uses attractive colours, texts, graphs and charts to break out complex information and make it more understandable for a common man.

\section{Infographics and Communicating Risks}

Communicating vital information, especially during an outbreak of pandemic disease, is always a challenge. During such a situation media adorns in shaping public opinion and perception of risks. (Welhausen, 2015) In the field of health, visual representation of emergent public outbreaks aid in 'improving attitudes and risk perception' (LaCour, Beyer, Finck, Miller, \& Davis, 2019). A common stratagem for risk dissemination to common people (non-experts), is through maps, bar and line graphs. Further, effective usage of colours plays a significant role in "communicating risk, improving comprehension, and increasing confidence in interpretation". (Turchioe, et al., 2019)

Researches indicate that layman understand risks better when presented in visuals (Ancker, Senathirajah, Kukafka, \& Starren, 2006); (Lipkus \& Hollands, 1999), as they fear that they have limited control over the threat as well as fear being hazardous to them and their loved ones (Welhausen, 2015). Consequently, taking cues from the various fields of psychology, usability, graphic design, and statistics, infographic aims to reduce barriers such as limited time and information overload to understand necessary information, (Otten, Cheng, \& Drewnowski, 2015) also, it persuades people for an attitude and behavioural change. (Bice, 2019) However, "less attention has focused on how these visuals shape risk perception, particularly in crisis and emergency risk communication scenarios, which frequently involve culturally divergent audiences." (Welhausen, 2015)

\section{THEORETICAL FRAMEWORK}

The risk communication primarily focuses on 'fear' - which trigger individual to engage in health behavioural change. The extended 
parallel process model (EPPM), a culmination of other risk and fear appeal theories and models highlights on perceived threat (involving perceived severity and susceptibility- appraisal of the threat), which motivates self-efficacy (appraisal of efficacy) among individuals. In other words, as risk increases individuals are motivated to engage in self-efficacy and response efficacy. (Lapinski, Neuberger, Grayson-Sneed, \& Gore, 2019); (Witte, 1992); (Li, 2018);(Chen \& Yang, 2019). The model provides a structure for understanding communicative health-related or risk messages effectively. (Maloney, Lapinski, \& Witte, 2011) Using EPPM constructs, the study explores how the effective usage of infographic is disseminating health-related information.

\section{METHOD}

Using a content analysis technique, the study collected infographics published in The Hindu and The Times of India from 1 January to 21 March 2020, till the day of announcement of 'Janata curfew', which was the initial period of the virus outbreak. The study identified $n=42$ in The Hindu (TH) and $n=143$ in The Times of India (TOI) newspaper using a consecutive sampling method. After employing inclusion and exclusion criteria, i.e. only infographics on COVID-19 health-based, $n=36$ and $n=97$ were identified in TH and TOI.

The selected infographic was categorised based on date, size of the infographic, headline, the level and type of infographic. The study modified the parameters of (Ghode, 2013), (Shin, 2016), and (Welhausen, 2015) into Level 1, which includes tables or bullet points, bar, pie or poll graph, line or fever-line, organisational or procedural flow chart; Level 2 includes themes or graphics or drawings such as conceptual diagrams, maps, typography, and symbolic interpretations and Level 3, is a combination of level 1 and 2 coupled with illustrations, stylistic representation of information. Further, the usage of colour and collectivism (group) and individualism (individuals). Additionally, to understand the message characteristics - using Extended Parallel Process Model (EPPM) parameters severity (the level of potential threats), vulnerability (negative consequences by the risk), self-efficacy and response-efficacy (to avoid and prevent threat) was analysed. The objectives of the study include:
RQ1: To analyse the percentage of coverage for infographics

RQ2: To identify the type and level of infographics

RQ3: To categorize the message characteristics of the infographics

\section{ANALYSIS}

The coverage of infographics in The Hindu and The Times of India found that The Times of India published more infographics in comparison to The Hindu.

\section{Percentage of Coverage}

In The Hindu, the study had taken $\mathrm{n}=36$ infographics for the analysis, which predominately focussed on COVID-19. The average editorial space of The Hindu during the selected dates is $67.79 \%$, and out of this $1.31 \%$ is devoted to infographics. The Hindu had two individual infographics, seven infographics published in the column 'data point' in opposite to editorial page (OpEd) and 27 infographics as part of the article (in-text infographics). (Table 1)

Table 1: Percentage of coverage

\begin{tabular}{|c|c|c|c|}
\hline The Hindu & $\begin{array}{l}\text { Number of } \\
\text { Infographic }\end{array}$ & $\begin{array}{l}\text { Infographic } \\
\text { Space (in } \\
\text { cms) }\end{array}$ & $\begin{array}{l}\text { Percentage } \\
\%\end{array}$ \\
\hline Data Point & 7 & 1607.25 & \\
\hline Infographic a & 2 & 288 & \\
\hline \multirow[t]{2}{*}{$\begin{array}{l}\text { In-text } \\
\text { Infographic b }\end{array}$} & 27 & 4286.25 & \\
\hline & 36 & 6182.5 & 1.31 \\
\hline \multicolumn{4}{|l|}{$\begin{array}{l}\text { The Times of } \\
\text { India }\end{array}$} \\
\hline Infographic a $^{\text {a }}$ & 72 & 7159 & \\
\hline \multirow[t]{2}{*}{$\begin{array}{l}\text { In-text } \\
\text { Infographic }{ }^{b}\end{array}$} & 25 & 9564.25 & \\
\hline & 97 & 16751.25 & 1.97 \\
\hline Inde & dent Infograph & & \\
\hline Infog & cs with article & & \\
\hline
\end{tabular}

In The Times of India, the study had taken $\mathrm{n}=97$ infographics. The average editorial space of TOI during the selected dates is $64.41 \%$, out of which $1.97 \%$ is devoted to infographics. The Times of India had 72 individual infographics and 25 infographics as part of the article (intext infographics). (Table 1)

\section{Level and Type of Infographics}

The Hindu had used predominantly used level 1 infographic $(n=21)$, i.e. table and bullet points infographic, followed by level $2(\mathrm{n}=12)$, i.e. theme-based and level $3(n=3)$, i.e. usage of illustrations to convey the message. The 
colours used in the infographics - are mostly red, followed by grey, yellow, orange, teal, blue and violet. Most of the infographics were text-centred $(n=29)$ rather than graphiccentred $(\mathrm{n}=7)$ (Table 2). Similarly, TOI had also used level 1 infographic $(n=49)$, followed by on "Tackling COVID-19 at ground level," "COVID-19: PM calls for social distancing, people's curfew", and "Quarantine facilities near airports soon, 24-hr helplines set up". Most of the news stories were thematic as it focussed on the larger group of people than individuals.

Table 2:Level, Type and message characteristics of infographic

\begin{tabular}{|c|c|c|c|c|c|}
\hline & The Hindu & TOI & & The Hindu & TOI \\
\hline Category & Count & & Category & Count & \\
\hline Level 1 & 21 & 49 & Severity & 22 & 69 \\
\hline Level 2 & 12 & 25 & Vulnerability & 19 & 69 \\
\hline Level 3 & 3 & 23 & Response-Efficacy & 13 & 51 \\
\hline Collectivism & 17 & & Self-Efficacy & 11 & 46 \\
\hline Individualism & 19 & 39 & Statistical Evidence & 22 & 60 \\
\hline Text-centred & 29 & 64 & & 17 & 55 \\
\hline Graphic-centred & 7 & 32 & & & \\
\hline
\end{tabular}

level 2 and $3(n=25 ; 23)$. The colours used in the infographics - are mostly red, black and blue. Most of the infographics were text-centred $(n=64)$ rather than graphic-centred $(n=32)$ (Table 2). The Times of India had utilised more infographics to convey 'risk' or 'threat' to public effectually.

\section{Frames}

The news stories were analysed from a public health model of reporting approach, which takes its roots from framing and agendasetting theory. (Coleman \& Perlmutter, 2005); (Coleman \& Thorson, 2002)

According to Entman (1993 and 2004), the frame looks into the specific problem, establishes the cause of the problem, arrives at a judgement and suggests remedies for the issues. Public health model also tries to define risk, develop and evaluate methods to prevent problems in order to alter the public health conditions in the society. Keeping this approach, news stories with infographics on COVID-19 were analysed from the perspective of the cause of the disease, risk factors and preventive strategies. (Kang, Gearhart, \& Bae, 2010).

The study found that in The Hindu, only one news story focussed on the cause of the disease - "A window into novel coronavirus transmission", while the rest of the stories covered the risk factors, which primarily focussed on the number of deaths, high alert and lockdown areas, and mapping of contact and the preventive strategies that highlighted
Meanwhile, in The Times of India, more news stories with infographics focussed on the risk factors and preventive measures rather than on the cause of the disease. The Times of India carried stories such as "WHO says China virus now global emergency", "Coronavirus slows in China, but gallops across the globe", "Avoiding ice-creams may not save you from coronavirus, but washing hands will", "Washing Hands is essential, but where is the soap for it?" and "Save lives with social distancing".

\section{Message Characteristics}

In terms of message characteristics, The Hindu focussed highly on the severity $(n=22)$ of the coronavirus by providing numbers of COVID19 cases reported in India and globally, followed by vulnerability $(n=19)$, responseefficacy $(n=13)$ and self-efficacy $(n=11)$. The newspaper focussed exceedingly on severity rather than on response-efficacy and selfefficacy. During a time of crisis, it is essential to provide information on self-care management as well as community care, which will enable citizens to prevent the spread of the disease. (Table 2)

In severity and vulnerability, The Hindu principally focussed on the number of deaths, vulnerable population, namely people with hypertension, diabetes and other comorbidity and also referring to previous disease outbreaks such as SARS. The keywords used in the infographic headlines carried were "closely related to SARS", "case count", "quick progression", and "rising cases". 
While, for response-efficacy and self-efficacy focussed on letting people know of traveling to affected areas such as "fear of flying" and "No-fly zone" and preventive measures such as washing hands frequently, wearing masks, measures to be followed while sneezing and coughing and maintaining social distancing and home quarantining.

Additionally, infographics headlines, which were carried along with the articles, tend to create fear and panic. The headlines such as "In the grip of fear", "the spread of a deadly virus", "the global spread", "the virus that shook the world", and "viral count" incline to generate fright in the reader's mind.

The newspaper had an infographic column 'Data Point', in the OpEd page, to provide statistical information, which also carried headlines such as "Spread of a deadly virus", "Anatomy of an outbreak", "Global emergency", "Testing Times", Going viral in Europe", "No-fly zone", and "Victim Profile". These headlines depicted severity and vulnerability of the regions affected by coronavirus as well as created panic and uncertainty.

However, "Preventive measures", and "Good old soap" in the FAQ page of The Hindu newspaper highlight the precautionary measures and how soap can be used instead of sanitizers.

Relatively, The Times of India also focussed on severity and vulnerability $(n=69)$ followed by response efficacy $(\mathrm{n}=51)$ and self-efficacy $(n=46)$. Nonetheless, it should be noted that TOI focussed on preventive measures comparatively more than The Hindu. (Table 2)

The severity and vulnerability infographics focussed on "mass evacuation", "1053 under scanner in State", "Major virus infection, fatality rises", "How worried should you be about coronavirus", "Elders, kids advised to stay home", "When age is a factor?" and "Heart Patients, Diabetes at Most Risk: WHO study". While, response-efficacy and self-efficacy focussed on "How to reduce risk", "How and when to wash hands", "What we know and what we don't $k n o w$ ", and "What if there is an infected person in city?"

Further, TOI had carried "TN Covid Tracker", "Corona Tracker", "Mapping outbreak", and "Tracking outbreak", on a daily-basis for informing about the number of deaths regionwise. However, the infographic was placed in a non-significant position in the newspaper.Most of TOI infographics predominately focused on risk factors "Battling Virus Spread", followed by preventive measures (n=34) - "Be Safe, Not Sorry", "To-do list", "Don't shake hands, Do Namaste", "How and When to wash hands", and "Shore up your defence" and cause of the disease $(\mathrm{n}=6)$ "Rallying to battle virus threat", and "How coronavirus hijacks your cells".

Further, unlike The Hindu, the word 'COVID-19', which was represented in capital letters, The Times of India used the lowerupper case to represent the word. The headlines in the infographics generated a fighting chi - "Fight so far", "Battling Covid-19", "Safety Net", "Testing times". The Hindu and The Times of India infographics focussed on providing statistical evidence comparatively more than an exemplar shred of evidence. Infographics were keen on representing the number of deaths and people infected, and countries affected rather than on responseefficacy and self-efficacy, which is the sole factor of 'social or physical distancing' during the spread of coronavirus.

\section{DISCUSSION}

The infographics in The Hindu and The Times of India noticeably shape the perception of risk. Though both newspapers, focused on severity and vulnerability, comparatively The Times of India, focused more on response and self-efficacy. Similarly, graphic-representation of data was predominantly high in TOI than in The Hindu. Graphics representation with the use of colour - red, metaphorically created anxiety and alarm. However, analysing interactive and animated infographic would have provided a perception of people's understanding of risk-based information.

To summarise, as a common axiom says, "A picture is worth a thousand words", a good infographic aid in processing information quickly by lowering barriers of complexity and also tell a story to its readers. They transform abstract data into appealing visuals for better understanding for a common man, and the power lies in the hands of a graphic designer. Though readers find infographics attractive but failed to promote message properly. (Hollander, 1994); (Few, 2017); 
(Siricharoen, 2013); (Albers, 2015); (Bresciani \& Eppler, 2015); (Welhausen, 2015); (Andrade \& Spinillo, 2016).

Further, as pointed out in the meta-analysis of fear appeals, fear stimuli have a direct or indirect effect on health behavioural changes.(Witte \& Allen, 2000)Infographics can radically change our perception of risk. The framing of the language, colour, headlines communicate a different message to the readers and at the same time, graphics could easily persuade readers to disregard the article. Nevertheless, as Albert Cairo, journalist and information designer stated visual or graphics can lie and mislead people. It is essential to understand this pitfall and read and understand the graphics and move toward 'evidence-driven visual communicator' and also be a responsible data journalist in the time of a disease outbreak.

\section{CONCLUSION}

Risk communication is reiterated in EPPM and public health models, which stress on the fact that coverage of health-related information affects individual's risk perception i.e. threat, which proportionally motivates for health behaviour depending on the health concern. Therefore, it is essential that media outlets emphasis more on self-efficacy of citizens through pictorial representation of data especially during global contagion for bringing in positive health-related behavioural change.

\section{REFERENCE}

Albers, M. J. (2015, August). Infographics and communicating complex information. In International conference of design, user experience, and usability, 267-276.

Ancker, J. S., Senathirajah, Y., Kukafka, R., \& Starren, J. B. (2006). Design features of graphs in health risk communication: A systematic review. Journal of the American Medical Informatics Association, 13 (6), 608-618.

Andrade, R., \& Spinillo, C. (2016). Understanding animated and interactive journalistic health infographics. Selected Readings of the 7th Information Design International Conference. The Brazilian Society of Information Design.
Balkac, M., \& Ergun, E. (2018). Role of Infographics in Healthcare. Chinese medical journal, 131 (20), 2514.

Bekhit, E. (2009). Infographics in the United Arab Emirates newspapers. Journalism, 10 (4), 492-508.

Bhattacharyya, M., \& Roy, P. (2016). Engaging Social Media in Health Communication Scope and Challenges of the 21st Century. Journal of Content, Community and Communication, 3 (2), 38-43.

Bice, C. (2019). The Relative Persuasiveness of Health Infographics. (Doctoral dissertation, Colorado State University. Libraries) .

Bresciani, S., \& Eppler, M. J. (2015). The pitfalls of visual representations: A review and classification of common errors made while designing and interpreting visualizations. Sage Open, 5 (4), 2158244015611451.

Brigham, T. J. (2016). Feast for the eyes: an introduction to data visualization. Medical reference services quarterly, 35 (2), 215-223.

Cairo, A. (2006). What should you show in a graphic. Design Journal, 99, 30-33.

Castaneda, A. (2018). Reporting on terror. Analysis of the use of infographics in news on the Barcelona terror attacks of 17 August, 2017, by print newspapers from the Basque Autonomous Community. Revista Latina de Comunicación Social, 73, 662-687.

Coleman, R., \& Perlmutter, D. D. (2005). Bullets as bacteria' Television news magazines' use of the public health model for reporting violence. Journalism, 6 (1), 24-42.

Damman, O. C., Vonk, S. I., van den Haak, M. J., van Hooijdonk, C. M., \& Timmermans, D. R. (2018). The effects of infographics and several quantitative versus qualitative formats for cardiovascular disease risk, including heart age, on people's risk understanding. Patient education and counseling, 101 (8), 1410-1418.

Dur, B. (2012). Analysis of data visualizations in daily newspapers in terms of graphic design. Procedia-Social and Behavioral Sciences, 51 (51), 278-283.

Dur, B., Filipczak-Bialkowska, Bresciani, S., Ge, J., Niu, Y., Othman, A., et al. (2014). Interactive infographics on the internet. Online Journal of Art and Design, 2 (4). 
Ferreira, J. (2014). Infographics: An introduction. Centre for Business in Society .

Few, S. (2017). The encyclopedia of humancomputer interaction. .

Gazizov, R. R., \& Fatykhova, M. H. (2019). Features of Infographics in the Russian Mass Media. Multidisplinary Social Science and Management, 10 (1), 7-9.

Ghode, R. (2013). Infographics in News presentation: A Study of its Effective Use in Times of India and Indian Express the Two Leading Newspapers in India. Journal of Business Management E Social Sciences Research, 1 (1), 35-43 .

Giardina, M., \& Medina, P. (2013). Information graphics design challenges and workflow management. Online Journal of Communication and Media Technologies, 3 (1), 108-124.

Hollander, B. A. (1994). Newspaper graphics and inadvertent persuasion. Visual Communication Quarterly, 1 (1), 8-9.

Kang, S., Gearhart, S., \& Bae, H.-S. (2010). Coverage of Alzheimer's disease from 1984 to 2008 in television news and information talk shows in the United States: an analysis of news framing. American Journal of Alzheimer's Disease $\mathcal{E}$ Other Dementias ${ }^{\circledR}, 25$ (8), 687-697.

Kosslyn, S. M. (1985). Graphics and human information processing: A review of five books. Journal of the American Statistical Association, 80 (391), 499-512.

LaCour, M., Beyer, E., Finck, J. L., Miller, M., \& Davis, T. (2019). Infographics Influence Attitudes and Risk Perceptions for Food Technologies. Meat and Muscle Biology, 3 (2), 55.

Lipkus, I. M., \& Hollands, J. (1999). The visual communication of risk. JNCI monographs, 1999 (25), 149-163.

McCrorie, A., Donnelly, C., \& McGlade, K. (2016). Infographics: healthcare communication for the digital age. The Ulster medical journal, 85 (2), 71 .
Meyer, S. (2009). A quantitative content analysis of errors and inaccuracies in missouri newspaper information graphics.

Miller, B. M., \& Barnett, B. (2010). Understanding of health risks aided by graphics with text. Newspaper Research Journal, 31 (1), 52-68.

Otten, J. J., Cheng, K., \& Drewnowski, A. (2015). Infographics and public policy: using data visualization to convey complex information. Health Affairs, 34 (11), 1901-1907.

Pasternak, S., \& Utt, S. H. (1990). Reader use \& understanding of newspaper infographics. Newspaper Research Journal, 11 (2), 28-41.

Salas, R. P. (2018). Evaluation of the infographics posted on Facebook by printed newspapers in Latin American countries during 2017. CUICIID 2018, 197.

Shin, H. (2016). Epidemic and risk communication: An analysis of strategic and graphic characteristics of infographics. Graduate Thesis and Dissertations, 15172. Iowa State University .

Siricharoen, W. V. (2013). Infographics: The new communication tools in digital age. In The International Conference on E-Technologies and Business on the Web (EBW2013), (pp. 169-174).

Smiciklas, M. (2012). The power of infographics: Using pictures to communicate and connect with your audiences. USA, USA: Que Publishing.

Turchioe, M. R., Myers, A., Isaac, S., Baik, D., Grossman, L., Ancker, J., et al. (2019). A Systematic Review of Patient-Facing Visualizations of Personal Health Data. Applied clinical informatics, 10 (04), 751-770.

Utt, S. H., \& Pasternak, S. (2000). Update on Infographics in American Newspapers. Newspaper Research Journal, 21 (2), 55.

Welhausen, C. A. (2015). Visualizing a nonpandemic: Considerations for communicating public health risks in intercultural contexts. Technical Communication, 62 (4), 244-257. 